\title{
BMJ Open Inpatient satisfaction with nursing care in a backward region: a cross-sectional study from northwestern China
}

\author{
Juxia Zhang, ${ }^{1}$ Limei Yang, ${ }^{2}$ Xiaoying Wang, ${ }^{3}$ Jiao Dai, ${ }^{1}$ Wenjing Shan, ${ }^{1}$ \\ Jiancheng Wang (iD ${ }^{4}$
}

To cite: Zhang J, Yang L, Wang $X$, et al. Inpatient satisfaction with nursing care in a backward region: a cross-sectional study from northwestern China. BMJ Open 2020;10:e034196. doi:10.1136/ bmjopen-2019-034196

- Prepublication history for this paper is available online. To view these files, please visit the journal online (http://dx.doi. org/10.1136/bmjopen-2019034196).

Received 12 September 2019 Revised 24 July 2020 Accepted 30 July 2020

Check for updates

(c) Author(s) (or their employer(s)) 2020. Re-use permitted under CC BY-NC. No commercial re-use. See rights and permissions. Published by BMJ.

${ }^{1}$ Nursing Department, Gansu Provincial Hospital, Lanzhou, China

${ }^{2}$ In-Patient Services Center, Gansu Provincial Hospital, Lanzhou, China

${ }^{3}$ Anorectal Department, Gansu Provincial Hospital, Lanzhou, China

${ }^{4}$ Elder Department, Gansu Provincial Hospital, Lanzhou, China

Correspondence to Dr Jiancheng Wang; 364954672@qq.com

\section{ABSTRACT}

Objectives The aim of the study was to examine the level of patient satisfaction with nursing care and identify the factors affecting satisfaction from the inpatient's perspective in a backward region of China.

Design This was a cross-sectional study.

Setting The study was conducted at a tertiary hospital located in northwest China.

Participants Patients admitted to the ward for at least 48 hours were chosen to participate in the survey.

Primary outcome measure The Newcastle Satisfaction with Nursing Care Scale was used. Data were collected from 219 patients.

Results The overall inpatient satisfaction with nursing care was $78.15 \pm 4.74$. Patients were more satisfied with nurses who respected their privacy and treated them as individuals $(67.7 \%)$. Patients were least satisfied with the type of information nurses gave them (11.7\%) and with the sufficient awareness of their needs. Patients who were married, had a history of hospitalisation, surgery and were taken charge of by junior nurses had higher satisfaction. Conclusions The overall level of patient satisfaction was moderate. Patient-centred individualised care and providing sufficient information model of care are needed. There was a need for nurses to be aware of patients' individualised care needs and to provide them with more information. This study may suggest/urge hospital administrators, policymakers and nurses to be more sensitive with patients' married status, history of hospitalisation and surgery, the professional title of in charged nurses when care is provided. Ultimately to achieve better outcome of patients' hospitalisation.

\section{BACKGROUND}

Patient satisfaction has been defined by scholars from different aspects. Swarup et al define it as people's expectation for healthcare services due to the requirements of health, disease, quality of life and other aspects. ${ }^{1}$ Berkowitz suggested that patient satisfaction is an individual's evaluation of the degree to which the medical services provided are in line with their expectations and preferences. ${ }^{2}$ Ahmed et al believe that patient satisfaction is the result of patients filtering medical service experience and

\section{Strengths and limitations of this study}

The current study used a valid and standardised instrument.

- This is the first study to evaluate inpatient satisfaction using Newcastle Satisfaction with Nursing Scale in a backward region of China.

- The small sampling might not likely to represent the patients in all Chinese hospitals.

- There is a possibility that patients' responses were influenced by social desirability.

evaluating the degree to which medical service experience meets their needs from their own unique perspective. ${ }^{3}$ Among them, most scholars believe that the best definition of patient satisfaction is an evaluation of medical services by patients based on the degree to which their expectations are met. ${ }^{4}$ In view of this expectation, the evaluation of patient satisfaction objectively reflects the quality of healthcare services which becomes a gold standard and widely used metric to measure hospital quality management. ${ }^{56}$

Patient satisfaction with nursing service is an important component of patient satisfaction. ${ }^{7}$ Risser defines patient satisfaction with nursing as the degree to which the patient's expectation of ideal care is consistent with the actual care. ${ }^{8}$ Eriksen defines it as a subjective evaluation made by patients according to their own expectations of nursing and their cognitive and emotional reactions to the interaction of actual receiving nursing services. ${ }^{9}$ The American Nurses Association defines it as a patient or his family staff's evaluation of the nursing care received. ${ }^{10}$ The above definitions are slightly different, but the consistent point is that patients' satisfaction with nursing is a subjective feeling, closely related to their expectation and perception of nursing quality. From the time of admission until discharge, nurses provide care for patients every day without fail and are 
involved in almost every aspect of a patient's care. Therefore, as main healthcare providers, nurses make a significant impact on patients' perceptions about their hospital experience. $^{7}$ If healthcare organisation managers are able to identify patient expectations, they could accordingly adjust the performance of services that they offer, in order to meet these expectations. ${ }^{11}{ }^{12}$ Therefore, it is urgently necessary to carry out surveys in health services to constantly measure patient healthcare satisfaction, to learn about their expectations, suggestions and feedbacks, so as to guide healthcare workers as to which items should be prioritised and which require alterations in the service. $^{13}$

In order to achieve the goal of high-care quality, decision makers should not only know whether a patient is satisfied but, more importantly, why the patient is not satisfied. That is, they should identify the factors affecting the patient's satisfaction with nursing services, so as to carry out care that meets the patient' needs. According to previous studies, factors such as age,${ }^{14}{ }^{15}$ gender, ${ }^{15-17}$ educational level, ${ }^{18}{ }^{19}$ length of hospital stay, type of admission, ${ }^{20}$ history of admission, patient's income level, type of admission rooms ${ }^{21}$ monthly household income, frequency of admission, and so on had a significant association with the level of satisfaction. ${ }^{22}$ To foster better individualised care, the factors influencing a hospitalised patient's perception of individualised care should be identified.

In China, there are 20918 hospitals of different levels with 20 million registered nurses. The average bed to nurse ratio is about 1:0.45. Of them, the 2232 tertiary public hospitals account for only $7.66 \%$ of the all-type health facilities, yet they provide nearly half $(42.5 \%)$ of the inpatient care. ${ }^{23}$ On average, the rate of one nurse per 1000 population is lower than the WHO standard of 2.28 per 1000 population. ${ }^{24}$ Excessive workloads lead to a lower job satisfaction in nurse staff across tertiary hospitals. ${ }^{23}{ }^{25}$ In such an environment, the patient satisfaction in tertiary hospitals needs more attention. The Ministry of Health of China formulated the 'Standards for Implementing Quality Nursing Services in Hospitals (Trial)' in 2010, which was aimed at providing patients with safe and high-quality nursing services. ${ }^{26}$ With these standards, the 'high quality nursing service project' was carried out nationwide. By the end of 2015, all tertiary hospitals in China had carried out the project, with $87.0 \%$ of them being tertiary A class hospitals and $82.6 \%$ were B class. ${ }^{27}$

At present, the results of surveys on the satisfaction of hospitalised patients with nursing service in China have rather been confusing. On one hand, patients in different facilities reported a high satisfaction about nursing service, as shown in table 1 .

These indicated that Chinese nursing services have continued to be improved with the implementation of the 'high-quality care project'. However, untruthful reports by the media and continuous occurrence of disputes and violence are inconsistent with the results of the satisfaction surveys. An analysis of workplace violence shows that $40.8 \%$ of hospital nurses in China have experienced different types of workplace violence. ${ }^{28}$ Zou's study showed that there was a high incidence $(59.7 \%)$ of workplace violence among nurses in Chinese tertiary

Table 1 Outcomes of patients' satisfaction in different provinces of China

\begin{tabular}{|c|c|c|c|c|c|c|c|}
\hline \multirow[b]{2}{*}{ Author } & \multirow{2}{*}{$\begin{array}{l}\text { Survey } \\
\text { date }\end{array}$} & \multirow[b]{2}{*}{ Province } & \multirow[b]{2}{*}{ Hospital included } & \multirow[b]{2}{*}{ Instrument } & \multicolumn{2}{|c|}{ Satisfaction } & \multirow[b]{2}{*}{ Effecting factors } \\
\hline & & & & & $\mathbf{n}$ & $\%$ & \\
\hline Guo et $a l^{67}$ & 2007 & 24 provinces & 71 hospitals & Self-designed & 4338 & 93.69 & Age, education level \\
\hline $\mathrm{Fu}^{48}$ & 2010 & Henan & 1 children hospital & NSNS & 110 & 85 & Age, education level \\
\hline $\mathrm{Nie}^{41}$ & 2013 & Shandong & $1 \mathrm{~B}$ class hospital & Self-designed & 626 & 78 & $\begin{array}{l}\text { Department, age, education level, } \\
\text { occupation, payment method, ADL }\end{array}$ \\
\hline Shan et $a l^{68}$ & 2013 & Heilongjiang & 30 hospitals & CNHSS & 1200 & 76 & Medical insurance \\
\hline $\mathrm{Hu}^{43}$ & 2013 & Gansu & 1 A class hospital & Self-designed & 400 & 80.9 & Environment \\
\hline $\mathrm{Guo}^{69}$ & 2014 & Shandong & 1A-class hospital & Self-designed & 298 & 79.8 & $\begin{array}{l}\text { Age, patients' position, culture, } \\
\text { income and reason for choosing the } \\
\text { hospital }\end{array}$ \\
\hline Liu and $\mathrm{Mao}^{40}$ & 2019 & $\begin{array}{l}11 \text { provinces in } \\
\text { western China }\end{array}$ & $\begin{array}{l}33 \text { county-level } \\
\text { hospitals, } 33 \\
\text { township hospitals }\end{array}$ & CNHSS & 9811 & 60 & Waiting time, medical expenses \\
\hline
\end{tabular}

ADL, ability of daily life; CNHSS, China National Health Service Surveys questionnaire; IAPSQGH, Improvement and Assessment of Patient Satisfaction Questionnaire in General Hospitals; NSNS, Newcastle Satisfaction with Nursing Scale. 
hospitals. ${ }^{29}$ Wang and Sun's study indicated that $6.67 \%$ of nurses had suffered violence in the workplace. ${ }^{30}$ Violence in these workplaces affects nurses' mental health, leading to job burn-out, ${ }^{31}$ and thus reduces the quality of nursing services. The frequent occurrence of workplace violence in hospitals directly reflects the dissatisfaction of patients with the quality of medical care. Thus, hospital-specific data are still required to provide evidence for crosscountry and cross-cultural comparisons of satisfaction and factors affecting satisfaction using standardised tools.

The backward region studied in this manuscript is the Gansu province, located in the northwest of China. Affected by the regional conditions, the development of economy, culture and information has been relatively less developed. According to China's comprehensive economic competitiveness development report, Gansu province was ranked 27th among the 31 provinces in China. ${ }^{32}$ With continuous development in the overall scale of hospitals in Gansu, the scope of service has been getting larger, and the number of patients received also gradually increasing. With the continuous improvement of people's requirements for service level, complaints from patients occur frequently. ${ }^{33}$ In light of this situation, hospital managers urgently need to understand the gap between patients' care needs and the capabilities of their hospital to providing care in a timely and dynamic manner. To our knowledge, ours is the first study in Gansu to use the Newcastle Satisfaction with Nursing Scale (NSNS) to measure satisfaction with nursing care. Thus, this study has two aims: (1) to assess patient satisfaction with nursing care using the NSNS instrument, so as to find out the gap between patients' expectations and hospitals' service provision; (2) to investigate into the factors affecting patient satisfaction with nursing care, so as to provide more accurate reference for hospital managers and relevant regulatory agencies.

\section{METHODS}

\section{Study design}

This study was a cross-sectional survey held in 2018. For the reporting purpose, Strengthening the Reporting of Observational Studies in Epidemiology checklist was used.

\section{Study settings and the participants}

This study was conducted at Gansu Provincial Hospital (GPH), a tertiary hospital with 1700 beds. The services at GPH include ear, nose and throat, surgery, outpatient clinic, emergency, gynaecology and obstetrics, paediatrics and neonatal intensive care unit, maternal and child health, physiotherapy, dental, radiology, traditional Chinese medicine, rehabilitation and internal medicine. GPH is also a teaching hospital for nursing, health officers, medicine, midwifery and pharmacy undergraduate and graduate students. The hospital has a total of 4070 employees, 1200 of which are nurses who provide healthcare in 60 nursing units. The hospitalised patients mainly come from residents and people in the surrounding cities and counties. Choosing the hospital to carry out the survey can better understand the expectations of patients from different social strata in Gansu.

The number of open beds in GPH is about 1500 , excluding departments such as paediatrics, intensive care units, emergency wards and VIP wards (about 200). The population of the study was calculated using the formula $\mathrm{N}=\mathrm{Z}^{2} \cdot \mathrm{P}(1-\mathrm{P})$ / $\mathrm{E}^{25}$ in which the symbols represent the following: a margin of error $(E)=5 \%$. In order to narrow the interval and make the estimation of effect quantity more accurate, we chose $99 \%$ as the confidence level, with $\mathrm{Z}=2.58$. Previous study showed that $90 \%$ patient satisfaction with nursing care. ${ }^{16}$ We calculated the sampling using the following: $\mathrm{Z}^{2} \cdot \mathrm{P}(1-\mathrm{P}) / \mathrm{E}^{2}=(2.58 * 2.58) \cdot 0.90(1-0.90) /(0.05 * 0.05)=6$. $65 * 0.09 / 0.0025=239$. Then we added $20 \%$ to the sample size for non-response or for selection bias, thus making the sample size $=288$ approximately. Patients should meet the following inclusion criteria: (1) $\geq 18$ years old; (2) admitted in the wards for at least 48 hours; (3) capable of independent communication; (4) voluntary participation. Patients were excluded on any one of the following: patients in intensive care unit; paediatric patients; emergency observation ward patients; VIP patients in selected wards. Medical, surgical, gynaecological and obstetrical, and ear, nose and throat wards were purposefully selected and based on the calculated sample size, the required number of patients from each ward was proportionally allocated. Finally, 291 patients were included for further analysis, and 32 were excluded with 12 of them being younger than 18 years old and 20 who refused to participate.

\section{Instruments}

The questionnaire included: (1) general demographic characteristics such as age, gender, educational status, marital status, monthly family income, history of admission, hospital length of stay, admission ward, professional title of the patient's nurse in charge; (2) NSNS checklist. The NSNS was developed by Thomas et al. ${ }^{34}$ The scale has been translated into different languages and has been applied in many studies. The Chinese version of the scale was tested for its validity and reliability by Jiao with the Cogent Validity index being 0.98 and Cronbach's alpha $0.97 .^{35}$ The NSNS includes two subscales: the Experience of Nursing Care Scale and the Satisfaction with Nursing Care Scale (SNCS). The two subscales can be applied either together or separately. In this study, the SNCS was applied, consisting of a total of 19 items and using a 5-point Likert scale. For assessing the degree of satisfaction, 'not at all', 'barely', 'satisfied', 'very' and 'completely' were scored from 1 to 5 respectively. Patient responses across all items were summed and transformed to yield an overall satisfaction score between 0 and 95 , which denotes none or complete satisfaction with all aspects of nursing care.

\section{Patient and public involvement}

The research questions and outcome measures were developed by the authors (JZ and JW) based on the 
NSNS checklist and through consulting with ward nurse managers who understood patients' priorities, experiences and preferences. Patients were recruited via their advisers (ward nurse managers) and were interviewed by the trained nurse students to evaluate their level of satisfaction. No patient was involved in the design and planning of the study. The main results will be disseminated to patients by means of health education.

\section{Data collection}

Five nursing students were trained previously by one of the authors (JZ). The training lasted for 2 days. On the first day, the students were trained to understand the meaning of each item of the questionnaire and, on the second, they were shown how to communicate with patients. After that, each student selected a patient in a specified department to conduct a presurvey using the questionnaire, and gave feedback regarding the survey process, so that the trainers could answer their questions in a timely manner.

At the time of admission, a lottery method was adopted by the nurse manager to randomly select patients. Then, the students made records and attended to the patients 48 hours later after their admission. A private room at the department was used to interview patients. Family members were present during some of the interviews at the request of patients. If the patient could not fill in the form due to various factors, the student would ask the questions and gave a certain amount of time for patients to make statements for each question. After each question, the student assisted to fill in the questionnaire according to the patient's answer. In addition, medical records were reviewed for certain variables such as hospital length of stay and history of admission. The study started in August 2018 through November of the same year and 291 patients completed the survey.

\section{Data analysis}

The data were collected and analysed with SPSS V.21.0. Patient satisfaction was described by the mean, SD, frequency and percentage. As the missing data were less than $5 \%$ in some items, we used listwise deletion to deal with them. Considering the study by Ahmed $e t a l^{21}$ we adopted the same method to use the mean satisfaction score as a cut-point to dichotomise satisfaction into 'satisfied' and 'not satisfied'. Based on the years of experience, the professional title of nurses was divided into junior (1-5 years) and senior (above 5 years). In addition to hospitalisation, we also checked whether patients had a history of hospitalisation in the past. Binary logistics regression analysis and backward stepwise method were used to screen variables that might affect patient satisfaction. The strength of the associations was described using OR and 95\% CI.

\section{RESULTS}

\section{Patients' characteristics}

Of the participants, the mean age was $45.59 \pm 15.96$. As seen in table $2,54.6 \%$ were male, $87.6 \%$ were married and $23.7 \%$ were primary school graduates; $33.7 \%$ were
Table 2 Sociodemographic characteristics and NSNS calculated score, for example $(n=291)$

\begin{tabular}{|c|c|c|c|}
\hline \multirow[b]{2}{*}{ Variables } & \multirow[b]{2}{*}{ Categories } & \multirow{2}{*}{$\begin{array}{l}\text { Frequency } \\
\mathrm{n}(\%)\end{array}$} & \multirow{2}{*}{$\begin{array}{l}\text { NSNS score } \\
\text { Mean (SD) }\end{array}$} \\
\hline & & & \\
\hline \multirow[t]{2}{*}{ Gender } & Male & $159(54.6)$ & $79.00 \pm 4.44$ \\
\hline & Female & $132(45.4)$ & $77.12 \pm 4.85$ \\
\hline \multirow{6}{*}{$\begin{array}{l}\text { Monthly family } \\
\text { income }(¥)^{\star}\end{array}$} & $<100$ & $1(0.3)$ & $78.0 \pm 0.35$ \\
\hline & $<1000$ & $17(5.7)$ & $77.52 \pm 4.05$ \\
\hline & 1000-2999 & $103(34.6)$ & $85.0 \pm 0.05$ \\
\hline & $3000-4999$ & $130(43.6)$ & $78.56 \pm 4.37$ \\
\hline & $\geq 5000$ & $39(13.1)$ & $77.0 \pm 6.45$ \\
\hline & $\geq 10000$ & $1(0.3)$ & $78.52 \pm 4.05$ \\
\hline \multirow[t]{3}{*}{ Marital status } & Single & $20(6.9)$ & $78.5 \pm 2.35$ \\
\hline & Married & $255(87.6)$ & $77.98 \pm 4.95$ \\
\hline & Others & $16(5.5)$ & $80.4 \pm 1.59$ \\
\hline \multirow{5}{*}{$\begin{array}{l}\text { Educational } \\
\text { status }\end{array}$} & Primary school & $69(23.7)$ & $78.27 \pm 4.01$ \\
\hline & High school & $146(50.2)$ & $77.90 \pm 4.53$ \\
\hline & Advanced diploma & $40(13.7)$ & $77.82 \pm 6.15$ \\
\hline & Bachelor's degree & 35 (12.0) & $79.11 \pm 4.96$ \\
\hline & Master's degree & $1(0.3)$ & $85.0 \pm 0.05$ \\
\hline \multirow[t]{5}{*}{ Admission ward } & Medicine & $99(33.7)$ & $78.62 \pm 4.93$ \\
\hline & Surgery & 78 (26.5) & $77.63 \pm 2.97$ \\
\hline & $\begin{array}{l}\text { Obstetrics and } \\
\text { gynaecology }\end{array}$ & $42(14.4)$ & $74.5 \pm 5.5$ \\
\hline & $\begin{array}{l}\text { Ophthalmology and } \\
\text { otorhinolaryngology }\end{array}$ & $18(6.2)$ & $79.77 \pm 3.13$ \\
\hline & $\begin{array}{l}\text { Rehabilitation } \\
\text { department }\end{array}$ & $22(7.6)$ & $80.86 \pm 5.13$ \\
\hline \multirow{2}{*}{$\begin{array}{l}\text { History of } \\
\text { admission }\end{array}$} & Yes & $146(50.2)$ & $78.76 \pm 4.57$ \\
\hline & No & $145(49.8)$ & $77.53 \pm 4.82$ \\
\hline \multirow{2}{*}{$\begin{array}{l}\text { Patients know } \\
\text { the name of } \\
\text { nurse in charge }\end{array}$} & Yes & $221(75.9)$ & $78.47 \pm 4.65$ \\
\hline & No & $70(24.1)$ & $77.14 \pm 4.82$ \\
\hline \multirow[t]{2}{*}{ Living area } & Urban & $146(50.2)$ & $77.98 \pm 4.08$ \\
\hline & Rural & $145(49.8)$ & $78.31 \pm 5.28$ \\
\hline \multirow{2}{*}{$\begin{array}{l}\text { Title of staff } \\
\text { nurse }\end{array}$} & Junior RN & $177(61.7)$ & $79.15 \pm 4.25$ \\
\hline & Senior RN & $114(38.3)$ & $76.56 \pm 4.98$ \\
\hline \multicolumn{2}{|c|}{ Mean satisfaction score } & \multicolumn{2}{|c|}{$78.15(\max 95) \pm 4.74$} \\
\hline
\end{tabular}

*US\$1 is $¥ 7.4$.

NSNS, Newcastle Satisfaction with Nursing Scale; RN, registered nurse.

admitted in a medical department, $43.6 \%$ had monthly family incomes between $¥ 3000$ and $¥ 4999$ (related to US\$436-US\$726). More than three-quarters (79\%) of the patients knew the name of their nurse in charge and more than half $(61.7 \%)$ were cared by junior registered nurses. Patients had variations in the duration of their hospital stays (2-36 days) with a mean of $7.20 \pm 5.69$ days. 
Table 3 Percentage distribution of items for satisfaction with nursing care in admitted patients at GPH

\begin{tabular}{|c|c|c|c|c|c|}
\hline Item & $\begin{array}{l}\text { Not at all } \\
\text { satisfied } \\
\text { n (\%) }\end{array}$ & $\begin{array}{l}\text { Barely } \\
\text { satisfied } \\
\mathrm{n}(\%)\end{array}$ & $\begin{array}{l}\text { Quite } \\
\text { satisfied } \\
\text { n (\%) }\end{array}$ & $\begin{array}{l}\text { Very } \\
\text { satisfied } \\
\text { n (\%) }\end{array}$ & $\begin{array}{l}\text { Completely } \\
\text { satisfied } \\
\text { n (\%) }\end{array}$ \\
\hline 1. The amount of time nurses spent with patient & 0 & $4(1.4)$ & $42(14.4)$ & $179(61.5)$ & $66(22.7)$ \\
\hline 2. How capable nurses were at their job & 0 & $1(0.3)$ & $16(5.5)$ & $156(53.6)$ & $118(40.5)$ \\
\hline 3. There always being a nurse around when needed & 0 & $2(0.7)$ & $58(19.9)$ & $164(56.4$ & $67(23.0)$ \\
\hline 4. The amount nurses knew about patient care & 0 & $1(0.3)$ & $38(13.1)$ & $193(66.3)$ & $59(20.3)$ \\
\hline 5. How quickly nurses came when patient called them & 0 & $1(0.3)$ & $30(10.3)$ & $123(42.3)$ & $137(47.1)$ \\
\hline 6. The way the nurses made patient feel at home & 0 & $1(0.3)$ & $47(16.2)$ & $187(64.3)$ & $56(19.2)$ \\
\hline $\begin{array}{l}\text { 7. The amount of information nurses gave to patient about } \\
\text { their condition and treatment }\end{array}$ & 0 & $5(1.7)$ & $124(42.6)$ & $102(35.1)$ & $60(20.6)$ \\
\hline 8. How often nurses checked to see if patients were well & 0 & $1(0.3)$ & $27(9.3)$ & $176(60.5)$ & $87(29.9)$ \\
\hline 9. Nurses' helpfulness & 0 & $1(0.3)$ & $26(8.9)$ & $192(66.0)$ & $72(24.7)$ \\
\hline 10. The way nurses explained things to patient & $1(0.3)$ & 0 & $29(10.0)$ & $166(57.0)$ & $95(32.6)$ \\
\hline $\begin{array}{l}\text { 11. How nurses helped put patient relatives or friends' } \\
\text { minds at rest }\end{array}$ & 0 & 0 & $41(14.1)$ & $161(55.3)$ & $89(30.6)$ \\
\hline 12. Nurses' manner in going about their work & 0 & 0 & $12(4.4)$ & $111(38.1)$ & $167(57.4)$ \\
\hline $\begin{array}{l}\text { 13. The type of information nurses gave to patient about } \\
\text { his/her condition and treatment }\end{array}$ & 0 & $3(1.0)$ & $97(33.3)$ & $157(54)$ & $34(11.7)$ \\
\hline 14. Nurses' treatment of patient as an individual & 0 & $1(0.3)$ & $14(4.8)$ & $78(26.8$ & $197(67.7)$ \\
\hline 15. How nurses listened to patient worries and concerns & 0 & $1(0.3)$ & $55(18.9)$ & $196(67.4)$ & $39(13.4)$ \\
\hline 16. The amount of freedom patient was given on the ward & 0 & 0 & $83(28.5)$ & $170(58.4)$ & $38(13.1)$ \\
\hline 17. How willing nurses were to respond to patient requests & 0 & $2(0.7)$ & $51(17.5)$ & $177(60.8)$ & $61(21)$ \\
\hline 18. The amount of privacy nurses gave patient & 0 & 0 & $36(12.4)$ & $78(26.8)$ & $177(60.8)$ \\
\hline 19. Nurses' awareness of patient needs & 0 & $3(1.0)$ & $130(44.7)$ & $130(44.7)$ & $28(9.6)$ \\
\hline
\end{tabular}

GPH, Gansu Provincial Hospital.

The hospital length of stay of inpatients in a surgery ward (an average of 11 days) was longer than that for medical inpatients (an average of 7 days). See table 2.

\section{Satisfaction with nursing care}

As shown in table 2, the average satisfaction score was 78.15 \pm 4.74 . Regarding nursing care, as shown in table 3, patients reported the highest satisfaction when nurses treated them as an individual $(67.7 \%)$ and respected their privacy $(60.8 \%)$. Patients were least satisfied with the type of information nurses gave them $(11.7 \%)$ and with latter's lack of awareness of the patient's needs $(9.6 \%)$. As shown in table 4, after dichotomising satisfaction into 'satisfied' and 'not satisfied', $60.5 \%$ of the study participants were satisfied with the care provided by nurses.

\section{Factors influencing satisfaction}

History of hospitalisation and history of surgery were significant factors influencing patient satisfaction with nursing care. A higher level of patient satisfaction was found in married patients with a history of admission $(p<0.05)$. Patients admitted in medical wards showed the highest satisfaction compared with those in other wards. The score without surgery was higher than that with surgery $(\mathrm{p}=0.045, \mathrm{OR}=0.64,95 \%$ CI 0.38 to 1.07$)$. The higher the nurse's professional title, the lower the score. The patient did not know the nurse in charge had a lower score $(\mathrm{p}=0.028, \mathrm{OR}=1.77,95 \%$ CI 0.98 to 3.19$)$ (table 5$)$.

\section{DISCUSSION}

Patients' satisfaction with hospital care is significantly associated with better patient safety, clinical effectiveness, ${ }^{36}$ health outcomes ${ }^{37}$ and less medical resource utilisation. ${ }^{38}$ In the current reform of China's healthcare system, we need to have a better understanding of what is associated with patient satisfaction, and what we can do to improve it. Comparably no study on patient satisfaction in northwest of China has been reported in English. The international research community has limited access to and understanding of patient satisfaction in this area. In this study, we use NSNS to investigate the level of inpatient satisfaction with nursing care and its associated factors in northwestern China. The results showed that the patient's overall satisfaction in nursing was $78.15+4.74$ (95 points are completely satisfied), and $60.5 \%$ of inpatients were satisfied with nursing services at GPH. Marital status, history of admission, history of surgery, knowing 
Table 4 Level of inpatient satisfaction with nursing services in a tertiary hospital of Gansu, China

\begin{tabular}{|c|c|c|}
\hline \multirow[b]{2}{*}{ Variables } & \multicolumn{2}{|c|}{ Level of satisfaction } \\
\hline & $\begin{array}{l}\text { Satisfied } \\
\text { (score } \geq 78) \\
\text { n (\%) }\end{array}$ & $\begin{array}{l}\text { Dissatisfied } \\
\text { (score <78) } \\
\mathrm{n}(\%)\end{array}$ \\
\hline \multicolumn{3}{|l|}{ Gender } \\
\hline Male & 105 (59.66) & $54(46.05)$ \\
\hline Female & $71(40.34)$ & $61(53.04)$ \\
\hline \multicolumn{3}{|l|}{ Marital status } \\
\hline Single & $12(6.82)$ & $8(6.96)$ \\
\hline Married & $158(89.77)$ & 97 (84.35) \\
\hline Others & 16 (9.09) & 0 \\
\hline \multicolumn{3}{|l|}{ Admission ward } \\
\hline Medicine & $69(39.20)$ & $29(25.22)$ \\
\hline Surgery & $41(23.29)$ & $36(31.30)$ \\
\hline $\begin{array}{l}\text { Obstetrics and } \\
\text { gynaecology }\end{array}$ & $11(6.25)$ & $31(26.96)$ \\
\hline $\begin{array}{l}\text { Ophthalmology and } \\
\text { otorhinolaryngology }\end{array}$ & $13(7.39)$ & $5(4.35)$ \\
\hline $\begin{array}{l}\text { Rehabilitation } \\
\text { department }\end{array}$ & $16(9.09)$ & $6(5.22)$ \\
\hline \multicolumn{3}{|l|}{ History of admission } \\
\hline Yes & 95 (53.98) & $51(44.33)$ \\
\hline No & $81(46.02)$ & $64(55.65)$ \\
\hline \multicolumn{3}{|l|}{ History of surgery } \\
\hline Yes & $81(43.02)$ & 66 (57.39) \\
\hline No & 95 (53.98) & $49(42.61)$ \\
\hline \multicolumn{3}{|c|}{ Know the nurse in charge } \\
\hline Yes & $140(79.55)$ & $81(70.43)$ \\
\hline No & $36(20.45)$ & $34(29.56)$ \\
\hline \multicolumn{3}{|l|}{ Title of nurse in charge } \\
\hline Junior & $121(68.75)$ & 56 (48.69) \\
\hline Senior & $55(31.25)$ & $59(51.30)$ \\
\hline \multicolumn{3}{|l|}{ Educational status } \\
\hline Primary school & $43(24.43)$ & $26(22.61)$ \\
\hline High school & $87(49.43)$ & $59(51.30)$ \\
\hline Advanced diploma & $22(12.50)$ & $18(15.65)$ \\
\hline Bachelor's degree & $23(13.07)$ & $12(10.43)$ \\
\hline Master's degree & $1(0.57)$ & 0 \\
\hline Total & $176(60.50)$ & 115 (39.50) \\
\hline
\end{tabular}

the nurse in charge and title of nurse in charge were all significantly associated with patient satisfaction.

The level of patient satisfaction $(60.5 \%)$ in our study was higher than the results obtained in other areas either in China or elsewhere, such as in Taiwan $(35 \%)^{39}$ Malaysia $^{22}$ and 11 western provinces in China $(60 \%)^{40}$; however, it was lower than that in Shandong, ${ }^{41}$ Jiangxi $^{42}$ and other cities in Gansu, China, ${ }^{33} 43$ and also in Spain ${ }^{44}$
Table 5 Factors influencing patients' satisfaction with nursing care

\begin{tabular}{lccll}
\hline Variables & B & SE & Significance & 95\% Cl \\
\hline Gender & 0.15 & 0.32 & 0.640 & 0.61 to 2.19 \\
\hline Marital status & -1.08 & 0.51 & 0.037 & 0.13 to 0.93 \\
\hline Admission ward & -0.02 & 0.12 & 0.839 & 0.76 to 1.24 \\
\hline History of admission & 0.29 & 0.38 & 0.045 & 0.67 to 2.29 \\
\hline $\begin{array}{l}\text { History of surgery } \\
\text { Know the nurse in }\end{array}$ & -0.60 & 0.29 & 0.049 & 0.30 to 0.98 \\
$\begin{array}{l}\text { charge } \\
\text { Title of nurse in charge }\end{array}$ & 0.99 & 0.30 & 0.001 & 1.13 to 4.35 \\
\hline \begin{tabular}{l} 
Educational status \\
\hline
\end{tabular} & -0.13 & 0.19 & 0.486 & 0.021 \\
\hline
\end{tabular}

and Australia. ${ }^{45}$ This might have been related to differences in sample size, region and the use of a different survey scale. Therefore, it is difficult to make an absolute comparison of these results. When the research findings were compared with studies conducted using the same scale internationally, the average score was higher than Turkey $(62.08+20.94),{ }^{5}$ Ethiopia $(63.9+17),{ }^{21}$ Poland $(74.98),{ }^{15}$ Jordan $(77.1+12.52){ }^{46}$ and Pakistan $(51 \%),{ }^{47}$ but lower than studies conducted in Beijing ${ }^{35}$ and Henan province $^{48}$ in China. A study from rural western China showed that patients in primary healthcare were relatively less satisfied with medical services than developed areas. ${ }^{49}$ Our study may have indicated this too.

Although the overall patient satisfaction was moderate, this study revealed that patients were mostly satisfied with nurses' attitude in treating them as an individual and respected their privacy. However, the fewest patients in the study were satisfied with the type of information nurses gave them $(11.7 \%)$ and a lack of awareness in their needs $(9.6 \%)$. The findings were consistent with the outcomes of other studies. ${ }^{50-53}$ It could be that, first of all, due to their heavy workload, nurses spent more time on completing doctor's orders and therapeutic work, less time is spent on communicating with patients and conducting health education. This might also result from the fact that in most Chinese hospitals there are no nurse assistants whose main task is the performance of basic nursing activities such as bathing, oral toilet, changing, and so on. ${ }^{54}$ Nurse staff in different professional layers need to perform various direct and indirect nursing activities. Moreover, hospitals in a less developed area may face a larger proportion of patients with a lower education level. ${ }^{49}$ They may have more demands of medical knowledge. However, with such a workload, nurses were eager to educate patients and therefore provide incomplete information that could not meet patients' needs. ${ }^{55}$ In various clinical settings, information is the decisive factor for good patient experience.$^{56}$ Poor communication between healthcare professionals and their patients is a key problem in the growing number of complaints against healthcare professionals worldwide. ${ }^{57}$ Therefore, investigating all aspects of patients' needs and providing them with care and information to meet their needs 
through communication plays an important role in improving patients' satisfaction. ${ }^{58}$

A better understanding of the factors affecting care quality can help hospital managers implement effective plans to improve service quality. ${ }^{59}$ In the current study, we find that married patients were more satisfied than others. This finding was in accord with a study conducted in Amhara Region ${ }^{60}$ which used the NSNS scale, and another study in China ${ }^{26}$ which used another scale. This could be that married patients were accompanied by their spouses who provided daily care and communicated with them. Therefore, they had relatively less demand from nurses. Prevalence of preoperative anxiety ranged from $60 \%$ to $80 \%$ in population, ${ }^{61}$ which had been commonly neglected by clinicians. ${ }^{62}$ Study has shown that patients who were well informed and understood the process had a better surgical experience. ${ }^{44}$ However, this might have not been well revealed in our study as patients with surgery showed less satisfaction with nursing services. It is suggested that patients need to be assessed regularly for anxiety during the preoperative visit and appropriate anxiety-reducing methods should be introduced. Nursing staff should attach importance to nurse-patient communication through assessing patient needs to provide health-related information and care services so as to meet patients' needs, ${ }^{58}$ thus enhancing their satisfaction.

Another factor that needs to be emphasised is that patients with a history of hospitalisation were found to be more satisfied than their counterparts, and similar results were found in other studies conducted in Ethiopia ${ }^{63}$ and China. ${ }^{26}$ This could be because patients who are hospitalised for the first time are unfamiliar with the nursing staff and hospital environment. They may have more needs for communication with nurses regarding their diseases and nursing services. For those with a history of admission, they have a certain understanding of their own diseases and health conditions, and are familiar with the hospital environment and ward nurses, and have a stronger sense of security than patients hospitalised for the first time. Our findings also showed that patients who knew their nurse in charge were significantly satisfied with nursing than those who did not. Study showed patients receiving continuity of care with the same nurse were more satisfied than those who did not. ${ }^{31}$ The findings can provide evidence for the value of nurses in nursing practice. Patients require more individualised care from nurses regarding education, communication and comfort, ${ }^{2}$ which will improve their well-being through reducing anxiety and depression, and also indirectly, through building trust and social support. ${ }^{64}$

Research shows that nurses' work experience is closely related to patient satisfaction. So it is helpful to provide guidance for rational allocation of nursing human resources to explore whether the composition of professional titles affects patient satisfaction. Tervo-Heikkinen et $a l$ s research shows that the working years of nurses are positively correlated with patient satisfaction. ${ }^{65}$ In China, the level of nurses is divided into professional titles corresponding to junior (1-5), intermediate (5-10) and senior (more than 10 years). The more nurses with a solid professional knowledge and rich working experience among nursing staff, the better the effect of nursing work. ${ }^{26}$ Research by Wang and Sun shows that patients' satisfaction with nursing professional skills is positively correlated with the proportion of nurses working for more than 5 years, and satisfaction with health education is positively correlated with the proportion of competent nurses. ${ }^{30}$ Han et al's survey shows that patients are most satisfied with nurses who have worked for $2-5$ years. ${ }^{66}$ Our findings also showed the same as the patients in the charge of junior nurses who have worked for less than 5 years were more satisfied than those in the charge of senior nurses. The reason may be that nurses who have worked for more than 5 years have rich clinical experience and better operating skills, but most of them have a sense of job burn-out, which has a negative impact on patient satisfaction. ${ }^{66}$ On the other hand, due to the different divisions of labour in GPH, nurses working for less than 5 years are mainly engaged in first-line clinical nursing, while senior nurses in some work related to ward organisation and management. Therefore, senior nurses have less communication with patients, thus affecting patients' satisfaction with their work. It indicated that nurse-patient communication plays an important role in the evaluation of patients' satisfaction with nursing work. ${ }^{67-69}$

This study has several strengths: the use of a standardised patient satisfaction scale and the first to evaluate patients' satisfaction using the scale in a less developed area of China. However, certain limitations should be noted too. First, the present study was conducted in one hospital context, which might limit the external validity of the results in other healthcare contexts. Future research should therefore investigate whether the questionnaire has the ability to demonstrate significant differences across hospitals in terms of their caring culture. Second, potentially relevant factors influencing patient satisfaction such as medical diagnosis, severity and duration of illness, and medication history were not included. Third, the study adopted self-reported questionnaires, so all answers were based on admitted patients, who might be afraid to speak out their real feelings that they thought might affect further nursing care they received.

\section{CONCLUSION}

The current study explored the level of patient satisfaction with nursing services and its associated factors in a backward region of China. It shows that the care needs of hospitalised patients are yet not satisfied to some extent. Meanwhile, patients' married status, history of hospitalisation and surgery, and professional title of nurses in charge when providing care are main factors affecting patients' satisfaction. The current finding will have direct implication for nurse professionals and nursing administrators. Nurses should establish a good relationship with patients 
through more communication. In daily nursing work, nurses should formulate corresponding plans according to the personal characteristics and care needs of patients so as to sufficiently meet patients' expectations.

Of course, besides nursing, many factors may also affect the patient's satisfaction, including patient staffing ratio, the use of health information technology, the amount of surgery in the hospital and the health teaching situation. Based on our experience, we suggest to conduct interviews with patient as a first step to learn what patients are most concerned with when seeking nursing services.

Acknowledgements We acknowledge the contribution of those patient advisers (ward nurse managers) who facilitated patient recruitment and two students (Wang Linna, Li Li, Gai Xiaojie, Pei Yun and Pei Xiaoyue) who collected the data. We also appreciate the help of the patients who participated in this study. We thank Mei Chunyuan, RN (clinical nurse; Wesley Hospital, Australia) and Kevin Miao (School of Foreign Languages and Literatures, Lanzhou University, China) for their hard work in improving the quality of English throughout the manuscript.

Contributors $L Y$ and $X W$ performed the survey. JW analysed and interpreted the patient data regarding satisfaction and effective factors. JZ was a major contributor in writing the manuscript. JD and WS were involved in supervision during data collection and data entry. All authors read and approved the final manuscript.

Funding This study is funded by Gansu Provincial Hospital fund (17GSSY1-5).

Disclaimer The funding has no role in the design of the study and collection, analysis, and interpretation of data and in writing the manuscript.

Competing interests None declared.

Patient and public involvement Patients and/or the public were not involved in the design, or conduct, or reporting, or dissemination plans of this research.

Patient consent for publication Not required.

Provenance and peer review Not commissioned; externally peer reviewed.

Data availability statement Data are available upon reasonable request. The data sets used and/or analysed during the current study are available from the corresponding author on reasonable request.

Open access This is an open access article distributed in accordance with the Creative Commons Attribution Non Commercial (CC BY-NC 4.0) license, which permits others to distribute, remix, adapt, build upon this work non-commercially, and license their derivative works on different terms, provided the original work is properly cited, appropriate credit is given, any changes made indicated, and the use is non-commercial. See: http://creativecommons.org/licenses/by-nc/4.0/.

ORCID iD

Jiancheng Wang http://orcid.org/0000-0001-9870-3123

\section{REFERENCES}

1 Swarup I, Henn CM, Gulotta LV, et al. Patient expectations and satisfaction in orthopaedic surgery: a review of the literature. J Clin Orthop Trauma 2019;10:755-60.

2 Berkowitz B. The patient experience and patient satisfaction: measurement of a complex dynamic. Online J Issues Nurs 2016;21:1.

3 Ahmed S, Miller J, Burrows JF, et al. Evaluation of patient satisfaction in pediatric dermatology. Pediatr Dermatol 2017;34:668-72.

4 Blank FSJ, Tobin J, Jaouen M, et al. A comparison of patient and nurse expectations regarding nursing care in the emergency department. J Emerg Nurs 2014;40:317-22.

$5 \mathrm{Kol} \mathrm{E}$, Arıkan F, İlaslan E, et al. A quality indicator for the evaluation of nursing care: determination of patient satisfaction and related factors at a university hospital in the Mediterranean region in turkey. Collegian 2018;25:51-6.

6 Al-Abri R, Al-Balushi A. Patient satisfaction survey as a tool towards quality improvement. Oman Med J 2014;29:3-7.

7 Seeber R. "The kind peace of mind culture" improves patient satisfaction. Rehabil Nurs 2012;37:286-91.

8 Risser NL. Development of an instrument to measure patient satisfaction with nurses and nursing care in primary care settings. Nurs Res 1975;24:45???51-52.
9 Eriksen LR. Patient satisfaction with nursing care: concept clarification. J Nurs Meas 1995;3:59-76.

10 American Nurses Association. 10 ANA quality indicators for acute care settings. Healthc Benchmarks 1999;6:138-9.

11 Davins J, Gens M, Pareja C, et al. El modelo de acreditación de atención primaria de Catalunya: un modelo válido. Medicina Clínica 2014;143:74-80.

12 ANCC. American nurses credentialing Center.Magnet recognition program model, 2017. Available: https://www.nursingworld.org/ organizational-programs/magnet/ [Accessed 17 Feb 2018].

13 Karaca A, Durna Z. Patient satisfaction with the quality of nursing care. Nurs Open 2019;6:535-45.

14 Land L, Suhonen R. Orthopaedic and trauma patients' perceptions of individualized care. Int Nurs Rev 2009;56:131-7.

15 Gutysz-Wojnicka A, Dyk D, Cudak E, et al. Measuring patient satisfaction with the Polish version of the Newcastle satisfaction with nursing scale. Scand J Caring Sci 2013;27:311-8.

16 Rose PM. Patients' characteristics informing practice: improving individualized nursing care in the radiation oncology setting. Support Care Cancer 2018;26:3609-18.

17 Alasad J, Abu Tabar N, AbuRuz ME. Patient satisfaction with nursing care: measuring outcomes in an international setting. J Nurs Adm 2015;45:563-8.

18 Köberich S, Feuchtinger J, Farin E. Factors influencing hospitalized patients' perception of individualized nursing care: a cross-sectional study. BMC Nurs 2016;15:14.

19 Atallah MA, Hamdan-Mansour AM, Al-Sayed MM, et al. Patients' satisfaction with the quality of nursing care provided: the Saudi experience. Int J Nurs Pract 2013;19:584-90.

20 Suhonen R, Land L, Välimäki M, et al. Impact of patient characteristics on orthopaedic and trauma patients' perceptions of individualised nursing care. Int J Evid Based Healthc 2010;8:259-67.

21 Ahmed T, Assefa N, Demisie A, et al. Levels of adult patients' satisfaction with nursing care in selected public hospitals in Ethiopia. Int J Health Sci 2014;8:375-83.

22 Zun $A B$, Ibrahim MI, Hamid AA. Level of satisfaction on service quality dimensions based on SERVQUAL model among patients attending 1 Malaysia clinic in Kota Bharu, Malaysia. Oman Med J 2018;33:416-22.

23 Duan M, Li D, Dong X. Analysis of job satisfaction among medical staff of public hospitals in Xingjiang. J Xinjiang Med Univ 2015;38:635-7.

24 Ministry of Health (MoH). China health statistical Yearbook. Beijing,China: Press of Peking Union Medical College, 2017.

25 Wang S, Rui J, Ke X, et al. Job satisfaction survey among 580 medical staff in public hopsitals in a City. Hei Long Jiang Med $J$ 2015;37:510-4.

26 Ministry of Health $(\mathrm{MoH})$. Ministry of health releases quality care service standards to strengthen Hospital clinical care. Available: http://www.china.com.cn/policy/txt/2010-12/23/content_21604283. htm

27 The National Nursing Development Plan (2016-2020), National Health Commission of the People's Republic of China 2016.

28 Fang PP, Ye Q, YX L, et al. Analysis on Workplace Violence in Hospital from Nurses' Perspective and Countermeasure(Chinese). Chinese Health Service Management 2016;33:255-8.

29 Zou QH. Research on the Current Situation and Risk Factors of Workplace Violence of Nurses in Level C Hospitals -Taking 3 Level C Hospitals as Examples(Chinese). Beijing University of Chinese Medicine,Master thesis, 2018.

30 Wang C, Sun $\mathrm{CH}$. Impacts of capability for work, mental health,and coping style of nurses on hospital workplace violence(Chinese). Chinese Journal of Public health 2015;23:941-5.

31 Zhang D, Lu D, Shi Y, et al. Impact of Patients Violence in Public Hospital on Job Burnout of Nurses(Chinese). Chinese Journal of Hospital Administration 2016;36:69-71.

32 National economic ranking of provinces in China, 2018. Available: http://www.sohu.com/a/307360333_120060910

33 Xing Y, Tang R, Du HF, et al. Satisfactory degree of inpatients in some Hospitasl in northwest region to nursing services. Chinese health industry 2016;06:67-70.

34 Thomas LH, McColl E, Priest J, et al. Newcastle satisfaction with nursing scales: an instrument for quality assessments of nursing care. Qual Health Care 1996;5:67-72.

35 Jiao J. Inpatient satisfaction with nursing care and its influencing factors in 3-A-Grade general hospitals in Beijing(Chinese). Beijing Xiehe Medical University,thesis, 2009.

36 Tsai TC, Orav EJ, Jha AK. Patient satisfaction and quality of surgical care in US hospitals. Ann Surg 2015;261:2-8. 
37 Doyle C, Lennox L, Bell D. A systematic review of evidence on the links between patient experience and clinical safety and effectiveness. BMJ Open 2013;3:e001570.

38 Tobis S, Wieczorowska-Tobis K, Talarska D, et al. Needs of older adults living in long-term care institutions: an observational study using Camberwell assessment of need for the elderly. Clin Interv Aging 2018;13:2389-95.

39 Khan M, Hassan R, Anwar S, et al. Patient satisfaction with nursing care. Rawal Medical Journal 2007;32:28-30.

40 Liu J, Mao Y. Patient satisfaction with rural medical services: a crosssectional survey in 11 Western provinces in China. Int $J$ Environ Res Public Health 2019;16:3968.

41 Nie SM. Study on inpatient satisfaction with nursing and influencing factors in some second A hospitals(Chinese). Master thesis,Shandong University, 2014

42 Liu X, Lu H, Wang Y, et al. Factors affecting patient satisfaction with ecdemic medical care: a cross-sectional study in Nanchang, China. Patient Prefer Adherence 2018;12:1373-82.

$43 \mathrm{Hu} \mathrm{L}$. Investigation on Satisfaction of Inpatients in a Hospital in Qingyang City,Gansu Province,China. Western traditional Chinese medicine 2014;11:87-90.

44 Sillero Sillero A, Zabalegui A. Satisfaction of surgical patients with perioperative nursing care in a Spanish tertiary care hospital. SAGE Open Med 2018;6:205031211881830.

45 Desborough J, Phillips C, Banfield M, et al. Impact of nursing care in Australian general practice on the quality of care: a pilot of the patient enablement and satisfaction survey (PESS). Collegian 2015;22:207-14

46 Jafar A, Alasad M, Muayyad M, et al. Patients' satisfaction with nursing care in Jordan. International Journal of Health Care Quality Assurance 2003;16:279-85.

47 Younas A, Sundus A. Patients' experiences and satisfaction about care provided by male nurses in medical surgical units in Islamabad, Pakistan: a pilot study. Nurs Forum 2018;53:12-19.

48 WJ F. Study of effects of family-centered care on quality of life in parents of children with cerebral palsy. Zhenzhou University,thesis, 2012.

$49 \mathrm{He} \mathrm{X}$, Li L, Bian Y. Satisfaction survey among primary health care outpatients in the backward region: an empirical study from rural Western China. Patient Prefer Adherence 2018;12:1989-96.

50 Lee TL, Crouse M, Gipson K. No-Pass zone: multidisciplinary approach to responding to patient needs. J Nurs Care Qual 2016;31:327-34.

51 Milutinović D, Simin D, Brkić N, et al. The patient satisfaction with nursing care quality: the psychometric study of the Serbian version of PSNCQ questionnaire. Scand J Caring Sci 2012;26:598-606.

52 Belayneh M. Inpatient satisfaction and associated factors towards nursing care at Felegehiwot Referral Hospital.Northwest Ethiopia:Amhara Regional State. Available: http://www.gjmedph. com/uploads/O7-Vo5No3.pdf

53 Chan B, Goldman LE, Sarkar U, et al. The effect of a care transition intervention on the patient experience of older Multi-Lingual adults in the safety net: results of a randomized controlled trial. J Gen Intern Med 2015;30:1788-94.
54 Wysokiński M, Ksykiewicz-Dorota A, Fidecki W. Scope of nursing care in Polish intensive care units. Biomed Res Int 2013;2013:1-9.

55 Atinyagrika Adugbire B, Aziato L. Surgical patients' perspectives on nurses' education on post-operative care and follow up in northern Ghana. BMC Nurs 2018;17:29.

56 Patient Information Forum. Making the case for information: the evidence for investing in high quality information for patients and the public, 2013. Available: https://www.pifonline.org.uk/wp-content/ uploads/2013/05/PiF-full-report-FINAL-new.pdf [Accessed $21 \mathrm{Jul}$ 2016].

57 Amutio-Kareaga A, García-Campayo J, Delgado LC, et al. Improving communication between physicians and their patients through mindfulness and Compassion-Based strategies: a narrative review. $J$ Clin Med 2017:6:33.

58 Jiang $\mathrm{S}$. The relationship between face-to-face and online patientprovider communication: examining the moderating roles of patient trust and patient satisfaction. Health Commun 2020;35:341-9.

59 Liu Y, Aungsuroch Y. Factors influencing nurse-assessed quality nursing care: a cross-sectional study in hospitals. J Adv Nurs 2018;74:935-45.

60 Kasa AS, Gedamu H. Predictors of adult patient satisfaction with nursing care in public hospitals of Amhara region, Northwest Ethiopia. BMC Health Serv Res 2019;19:52.

61 Woldegerima YB, Fitwi GLYimer HT, et al. Prevalence and factors associated with preoperative anxiety among elective surgical patients at University of Gondar Hospital.Gondar,Northwest Ethiopia,A crosssectional study. Int J Surg Open 2018;10:21-9.

62 Pereira L, Figueiredo-Braga M, Carvalho IP. Preoperative anxiety in ambulatory surgery: the impact of an empathic patient-centered approach on psychological and clinical outcomes. Patient Educ Couns 2016;99:733-8.

63 Sharew NT, Bizuneh HT, Assefa HK, et al. Investigating admitted patients' satisfaction with nursing care at Debre Berhan referral hospital in Ethiopia: a cross-sectional study. BMJ Open 2018;8:e021107.

64 Greenhalgh J, Gooding K, Gibbons E, et al. How do patient reported outcome measures (PROMs) support clinician-patient communication and patient care? A realist synthesis. J Patient Rep Outcomes 2018;2:42.

65 Tervo-Heikkinen T, Kvist T, Partanen P, et al. Patient satisfaction as a positive nursing outcome. J Nurs Care Qual 2008;23:58-65.

66 Han C-H, Connolly PM, Canham D. Measuring patient satisfaction as an outcome of nursing care at a teaching hospital of southern Taiwan. J Nurs Care Qual 2003;18:143-50.

67 Guo YH, Jiao J, Zheng XJ, et al. A survey of inpatient satisfaction with nursing care in 24 districts of China(Chinese). Chinese Journal of Nursing 2008;43:293-8.

68 Shan L, Li Y, Ding D, et al. Patient satisfaction with hospital inpatient care: effects of trust, medical insurance and perceived quality of care. PLoS One 2016;11:e0164366.

69 Guo M. A Survey on Inpatient Satisfaction and Influence Factors Analysis in a Tertiary Hospital,Master thesis, Dalian Medical University, 2015. 